\title{
Comparison of Three Statistical Downscaling Methods and Ensemble Downscaling Method Based on Bayesian Model Averaging in Upper Hanjiang River Basin, China
}

\author{
Jiaming Liu, ${ }^{1}$ Di Yuan, ${ }^{1}$ Liping Zhang, ${ }^{1,2}$ Xia Zou, ${ }^{1,3}$ and Xingyuan Song ${ }^{1}$ \\ ${ }^{1}$ State Key Laboratory of Water Resources and Hydropower Engineering Science, Wuhan University, Wuhan 430072, China \\ ${ }^{2}$ College of Tourism Culture and Geographical Science, Huanggang Normal University, Huanggang 438000, China \\ ${ }^{3}$ Shanghai Branch of Yangtze River Water Resources Protection Bureau, Shanghai 200120, China \\ Correspondence should be addressed to Liping Zhang; zhanglp@whu.edu.cn
}

Received 25 June 2015; Revised 29 September 2015; Accepted 11 October 2015

Academic Editor: Alexander Gelfan

Copyright (C) 2016 Jiaming Liu et al. This is an open access article distributed under the Creative Commons Attribution License, which permits unrestricted use, distribution, and reproduction in any medium, provided the original work is properly cited.

\begin{abstract}
Many downscaling techniques have been developed in the past few years for projection of station-scale hydrological variables from large-scale atmospheric variables to assess the hydrological impacts of climate change. To improve the simulation accuracy of downscaling methods, the Bayesian Model Averaging (BMA) method combined with three statistical downscaling methods, which are support vector machine (SVM), BCC/RCG-Weather Generators (BCC/RCG-WG), and Statistics Downscaling Model (SDSM), is proposed in this study, based on the statistical relationship between the larger scale climate predictors and observed precipitation in upper Hanjiang River Basin (HRB). The statistical analysis of three performance criteria (the Nash-Sutcliffe coefficient of efficiency, the coefficient of correlation, and the relative error) shows that the performance of ensemble downscaling method based on BMA for rainfall is better than that of each single statistical downscaling method. Moreover, the performance for the runoff modelled by the SWAT rainfall-runoff model using the downscaled daily rainfall by four methods is also compared, and the ensemble downscaling method has better simulation accuracy. The ensemble downscaling technology based on BMA can provide scientific basis for the study of runoff response to climate change.
\end{abstract}

\section{Introduction}

Global climatic changes could lead to changes in regional water availability. Such hydrologic changes will affect nearly every aspect of human well-being, from agricultural productivity, energy use, flood control, to municipal and industrial water supply, fish and wildlife management. The tremendous importance of water in both society and nature underscores the necessity of understanding how a change in global climate could affect regional water supplies [1]. General circulation models (GCMs), which are numerical coupled models and describe the atmospheric processes through mathematical equations, have been one of the most important tools for studying climate change. GCMs represent various earth systems including the atmosphere, oceans, land surface, and sea ice and offer considerable potential for studying climate change. At large scales, GCMs which have been steadily evolving over several decades are able to simulate the most important features of the global climate, and simulations are most reliable over the tropical regions [2]. However, these same models perform poorly at smaller spatial and temporal scales relevant to regional impact analyses [3, 4]. Because the spatial resolution of GCMs grids is too coarse to resolve many important subgrid scale processes, GCMs outputs are often unreliable at individual grid and subgrid box scales $[1,5]$.

One possible solution to overcome this problem is to downscale the output from GCMs to a higher resolution in space/time and then to use scenario output in local water management. The basic idea of downscaling is to transfer large-scale changes in atmospheric variables (predictors), reliably simulated from GCMs, to local weather series (predictands) [6]. To deal with this issue several downscaling methodologies, such as dynamic downscaling and statistical downscaling, have been developed. Dynamic 


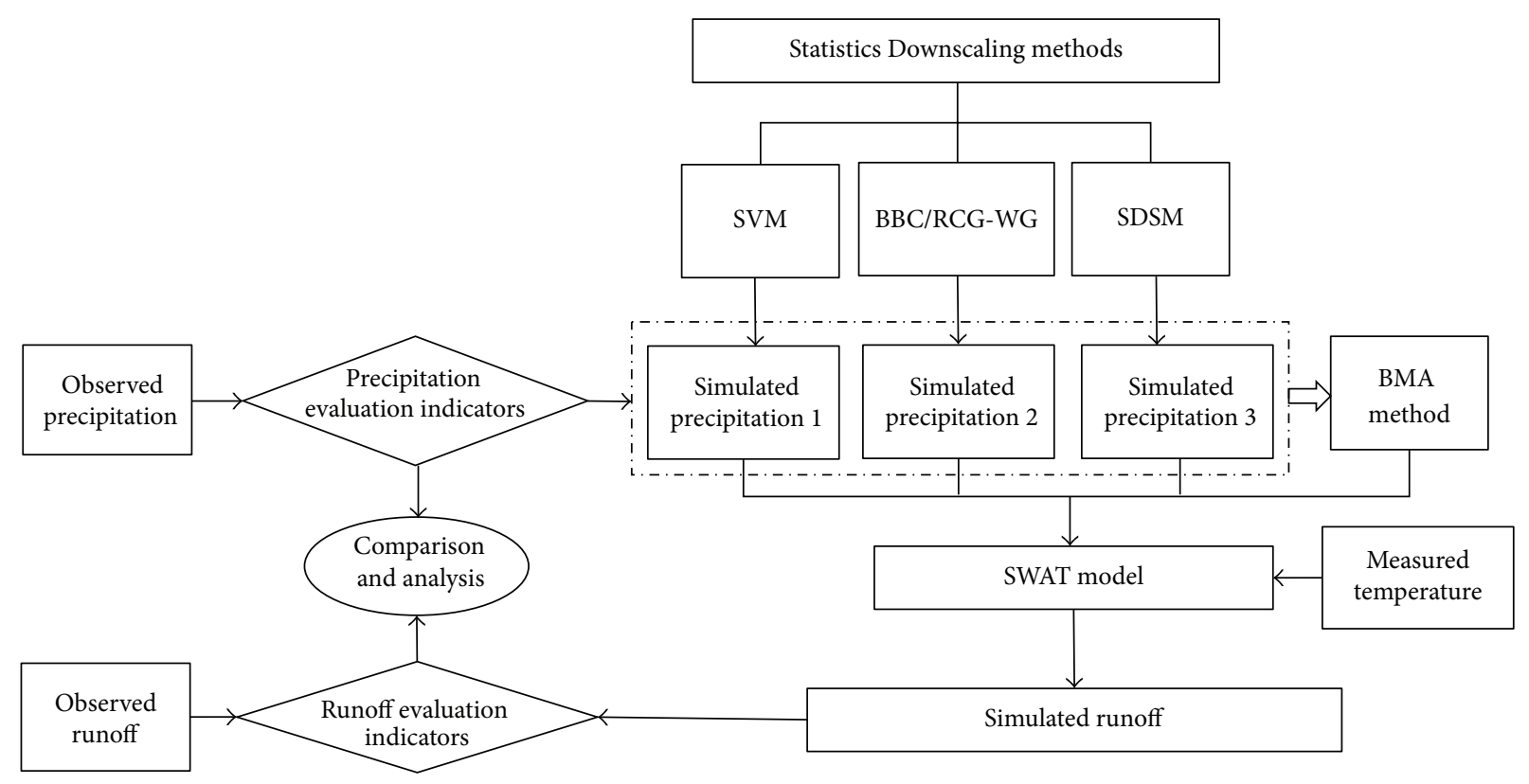

FIGURE 1: The technical route of this study.

downscaling refers to the use of regional climate models (RCMs), or limited-area models (LAMs) which employ largescale and lateral boundary conditions from GCMs to produce higher resolution outputs [7]. The statistical downscaling methodology has many obvious drawbacks like the uncertain assumption of applicability in a future climate, but it is a computationally cheap and statistically sound complement to dynamical downscaling. It is notable that predictor and predictand can be the same parameter on different scales, but statistical methods can freely select any variable as predictor as long as it can be motivated. Several existing statistical downscaling methods have been applied in different climate regions [1, 4]. More sophisticated statistical downscaling methods are generally classified into three groups [7]: regression models (e.g., CCA, SVM), weather typing schemes, and weather generators (e.g., LARS-WG, BCC/RCG-WG). Studies comparing different statistical downscaling methods are now relatively common $[4,8-10]$. The results of these studies have shown that different methods have different performance in a certain area, and a certain method has different performance in different study areas. Since different methods have strengths in capturing different aspects of the downscaling, combining the results from diverse methods by weighting procedures can present a better performance than any individual method [11-13].

The early combination techniques employed such tools as simple model average, linear regression, and artificial neural network [14-17]. These methods use a set of deterministic weights to combine multiple model outputs, and the weights in such combination can take any arbitrary real (positive or negative) values that lack physical interpretations [18]. Bayesian Model Averaging (BMA) came to prominence in statistics in the mid-1990s, and Madigan and Raftery [19] were the first to propose this method for combining predictions. Subsequently, Raftery [20] and Draper [21] gave more detailed discussion about BMA. It has been applied in diverse fields such as economics [22], biology [23], ecology [24], public health [25], toxicology [26], meteorology [27], and management science [28]. In many case studies, BMA produces accurate and reliable predictions and was shown to be a better scheme than other model-combining methods [29-31]. In recent years, hydrologists have also applied BMA to hydrologic modelling, such as groundwater [32] and rainfall-runoff modelling [18, 33, 34].

The BMA method has the ability to improve the accuracy of the prediction; only a few studies have applied BMA to downscaling methods. For example, Yang et al. [35] used the BMA ensemble method to reduce the uncertainties in lateral boundary forcing and improve model performance in regional climate downscaling. Three statistical downscaling models are combined together by using BMA method in this study, which aims to investigate the potential use of BMA in downscaling GCM simulations in the upper Hanjiang River Basin (HRB), China. The three statistical downscaling techniques used here are as follows: (i) support vector machines (SVM) model [36, 37]; (ii) BCC/RCGWeather Generators (BCC/RCG-WG) [38, 39], and (iii) Statistics Downscaling Model (SDSM) [40]. More specifically, the following objectives have been set for this paper: (1) to establish the statistical relationship between large-scale circulation (using NCEP/NCAR reanalysis data) and precipitation in the upper HRB by using these three downscaling methods; (2) to combine the three downscaling models by using BMA method; and (3) to assess the performance of ensemble downscaling method based on BMA for rainfall and runoff modelled by SWAT model in the upper HRB. The technical route of the research in this paper is described in Figure 1. 


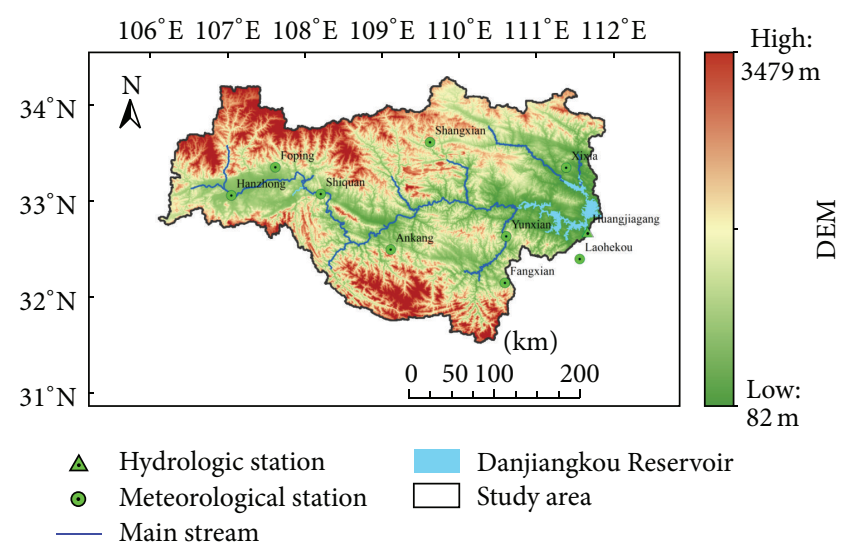

Figure 2: Location of the meteorological and hydrological stations in upper HRB.

This paper is organized as follows. First, the details of the study area, station-observed data, NCEP/NCAR reanalysis data, and digital watershed data used in the study are described. This is followed by a description of the downscaling methods, BMA method, and hydrological model. The results are then presented followed by a discussion and finally the conclusions are presented.

\section{Study Area and Data}

2.1. Study Area. The selected area for this study is upper HRB as shown in Figure 2. It is located in Shanxi Province and Hubei Province of China and the total area is approximately $95200 \mathrm{~km}^{2}$. The length of main stream is $925 \mathrm{~km}$ which takes up $59 \%$ of the total length of the Hanjiang River. The basin has a subtropical climate and the area is humid with fairly high precipitation. The mean annual rainfall is $904 \mathrm{~mm}$. The precipitation distribution in this area changes greatly in time and space, and the amount of precipitation is mainly concentrated in summer.

\subsection{Data Collection}

2.2.1. Station-Observed Data. The meteorological data series of nine stations from 1961 to 2009 is selected in the study area. The observed data are provided by the Shared Services Network of the China Meteorological Administration. The data include daily average temperature, maximum temperature, minimum temperature, precipitation, relative humidity, average wind speed, and sunshine hours. The monthly streamflow data of Danjiangkou (DJK) Reservoir which controls the watershed, from 1961 to 2009, is also included. The locations of these meteorological stations and hydrologic station are shown in Figure 2.

2.2.2. NCEP/NCAR Reanalysis Data. The atmospheric predictor data for 1961-2009 used to calibrate and validate the downscaling methods were obtained from the NCEP/NCAR reanalysis data at $2.5^{\circ}$ by $2.5^{\circ}$ grids. The upper HRB covers 12 grids (seen in Figure 3). The NCEP grids are interpolated spatially into the meteorological stations by using the inverse distance weighting method.

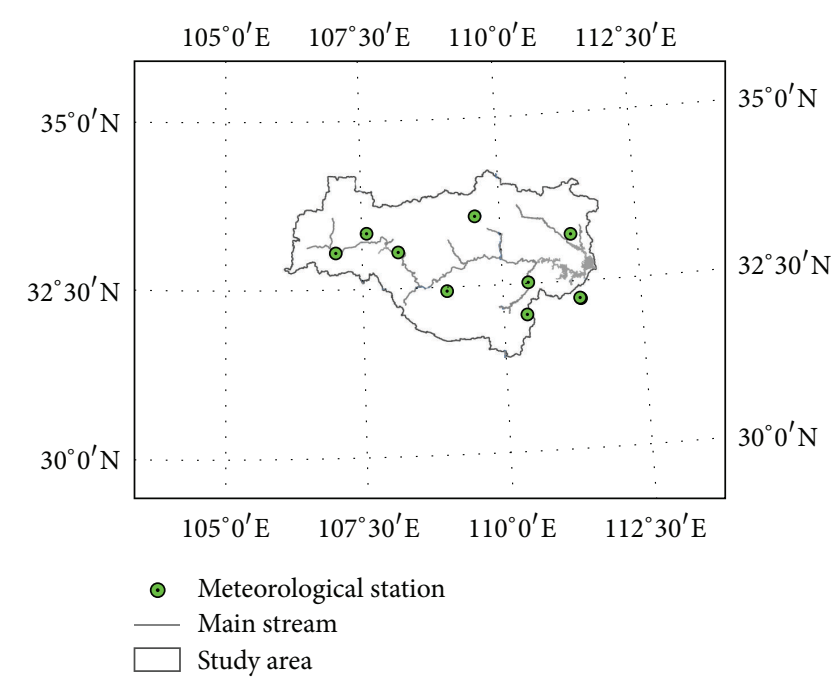

FIgURE 3: The NCEP grids of upper HRB.

When establishing the statistical downscaling models, selection of predictors is one of the most critical steps and three criteria should be followed [5]. The complexity of the models can be effectively reduced while the predictors that have significant impacts on the predictands are selected. At the same time, the predictors that have no significant impacts on the predictands should be excluded to eliminate redundant information and avoid introducing additional interference factors. According the previous studies [5, 41], 10 alternative predictors are chosen by stepwise regression and correlation analysis combining the criteria and climate characteristics of HRB based on NCEP reanalysis data including 26 atmospheric circulation factors for each grid point (seen in Table 1).

2.2.3. Digital Watershed Data. This study uses the GTOPO30 digital elevation model (DEM) provided in downloadable form by the US Geological Survey (USGS). Based on these data, the watershed DEM and stream networks are extracted and divided into subwatersheds (seen in Figure 1). The soil spatial distribution data are obtained from the soil database of the Institute of Soil Science of Nanjing, China Academy of Sciences, and are classified according to the soil subclasses under the class of land resources and environment in the Chinese Resources and Environment Database. The spatial distribution data of land use are obtained from the national land cover framing TIF maps ( $30 \mathrm{~m}$ spatial resolution) provided by the State Bureau of Surveying and Mapping and are classified into 12 categories according to the Soil and Water Assessment Tool (SWAT) parameter database of land use in the United States.

\section{Methods}

\subsection{Statistical Downscaling Methods}

3.1.1. SVM. The foundations of SVM have been developed by Vapnik [42, 43], initially for optical character recognition. In recent times, SVM approach is recognized for its ability to 
TABLE 1: NCEP alternative predictors.

\begin{tabular}{lcc}
\hline Predictors & Physical meaning & Units \\
\hline Temp & Near-surface air temperature & $\mathrm{K}$ \\
p500 & $500 \mathrm{hPa}$ geopotential height & $\mathrm{m}$ \\
p850 & $850 \mathrm{hPa}$ geopotential height & $\mathrm{m}$ \\
r500 & Relative humidity at $500 \mathrm{hPa}$ height & $\%$ \\
r850 & Relative humidity at $850 \mathrm{hPa}$ height & $\%$ \\
mslp & Mean sea level pressure & $\mathrm{Pa}$ \\
p5_u & Zonal velocity at 500 hPa height & $\mathrm{m} / \mathrm{s}$ \\
p8_u & Zonal velocity at $850 \mathrm{hPa}$ height & $\mathrm{m} / \mathrm{s}$ \\
p5_v & Meridional velocity at $500 \mathrm{hPa}$ height & $\mathrm{m} / \mathrm{s}$ \\
p8_v & Meridional velocity at $850 \mathrm{hPa}$ height & $\mathrm{m} / \mathrm{s}$ \\
\hline
\end{tabular}

capture nonlinear regression relationships between variables $[36,37,44]$. The SVM model has been used as a downscaling technique for predicting precipitation of different regions and proven to be effective for downscaling precipitation [41, 45]. The least square support vector machine (LS-SVM) which provides a computational advantage over standard SVM [46] is a least squares version of SVM, where the solution to the optimization problem is found by solving a set of linear equations instead of a convex quadratic programming for classical SVMs. Because the final decision function of SVM is only determined by support vector, its complex degree depends on the number of support vectors, rather than the dimensions of the sample space (factor), so more forecast factors reflecting more space change in the atmosphere can be chosen. In this study, the optimal model is established through parameter (between predictors and predictands) optimization using 10 primary predictors as prediction factors of the SVM.

3.1.2. BCC/RCG-WG. BCC/RCG-WG is named for the weather generator developed by Beijing Climate Center of China Meteorological Administration (CMA) and Regional Climate Group at the University of Gothenburg [39]. Due to its stochastic framework for the daily climatic variables, BCC/RCG-WG allows us to generate arbitrarily long series to meet the needs of impact assessment and risk analysis of climate change, and so forth. Liao et al. [38, 39] have shown that BCC/RCG-WG can successfully simulate daily precipitation and nonprecipitation variables including maximum temperature, minimum temperature, and sunshine hours in China. The input data is temperature decreasing degree and precipitation increasing/decreasing percentage. In this study, the input data are calculated from the monthly temperature and precipitation from 1991 to 2009 and the monthly mean across the years during this period.

3.1.3. SDSM. The SDSM is a decision-support tool for assessing local climate-change impacts using a robust statistical downscaling technique. It was developed by Wilby et al. [40]. SDSM uses a hybrid stochastic weather generator and a multilinear regression method to simulate local variables of regional circulation and atmospheric moisture predictors [47]. The model has been applied in many catchments in North America [48] and Europe [40, 49]. Previous studies have shown that SDSM has superior capability to capture local-scale climate variability $[9,10,40]$. In this study, SDSM is established using NCEP/NCAR reanalysis data and observed data. The first 30 years (1961-1990) is used for calibrating the model, and the remaining 19 years (19912009) is used to validate the model. The corresponding predictors for precipitation and average temperature of each meteorological station are filtered out, respectively, from the 10 primary predictors by screening of variables in SDSM application program and partial correlation analysis. During downscaling precipitation, the process of the model is conditional because the amount of precipitation is the first condition to determine the probability of wet days and the probability of wet days is related to the large-scale predictors.

\subsection{Ensemble Downscaling Method Based on BMA}

3.2.1. Bayesian Model Averaging. The BMA probability density function (PDF) is a weighted average of the conditional PDFs given each of the individual models, weighted by their posterior model probabilities. BMA possesses a range of theoretical optimality properties and has shown good performance in a variety of simulated and real data situations [31]. Consider a quantity $P$ to be predicted on the basis of training data $D=[X, Y]$ ( $X$ denotes input forcing data and $Y$ stands for the observational rainfall data). $f=\left[f_{1}, f_{2}, \ldots, f_{k}\right]$ is the ensemble of the $K$-member predictions. The posterior distribution of the BMA prediction is thus given as

$$
p(P \mid D)=\sum_{k=1}^{K} p\left(f_{k} \mid D\right) \cdot p_{k}\left(P \mid f_{k}, D\right),
$$

where $p\left(f_{k} \mid D\right)$ is the posterior probability of the prediction $f_{k}$ given the training data $D$ and reflects how well model $f_{k}$ fits $Y$. The posterior model probabilities add up to one, and they can thus be viewed as weights. $p_{k}\left(P \mid f_{k}, D\right)$ is the conditional PDF of the prediction and $P$ conditional on $f_{k}$ and training data $D$, and it is always assumed to be a normal PDF and is represented as $g\left(P \mid f_{k}, \sigma_{k}^{2}\right) \sim N\left(f_{k}, \sigma_{k}^{2}\right)$, where $\sigma_{k}^{2}$ is the variance associated with model prediction $f_{k}$ and observations $Y$. In order to make this assumption valid, some techniques such as Box-Cox transformation are needed to make the data approximately normally distributed and to narrow the data range. In the case that the observations and individual model predictions are all normally distributed, the BMA predictive model is then

$$
\begin{aligned}
E(P \mid f, D) & =\sum_{k=1}^{K} p\left(f_{k} \mid D\right) \cdot E\left[g\left(P \mid f_{k}, \sigma_{k}^{2}\right)\right] \\
& =\sum_{k=1}^{K} w_{k} \cdot f_{k},
\end{aligned}
$$

where $w_{k}$ is the posterior probability of forecast $f_{k}$ being the best one and is based on forecast $f_{k}$ 's performance in the training period. The $w_{k}$ 's are probabilities and so they are nonnegative and add up to 1 ; that is $\sum_{k=1}^{K} w_{k}=1$. 
3.2.2. EM Algorithm for BMA Parameter Estimation. To estimate BMA weight $w_{k}$ and model predication variance $\delta_{k}^{2}$, the Expectation-Maximization (EM) algorithm has proved to be an efficient technique for BMA calculation based on the assumption that $K$-member predictions are normally distributed [33].

\subsection{Hydrological Model}

3.3.1. Introduction of SWAT. The Soil and Water Assessment Tool (SWAT) is chosen to simulate the hydrological processes in this study. The SWAT is a newly developed model that can be applied to a large ungauged rural watershed with hundreds of small subwatersheds. It was developed in the early 1990s by the US Department of Agriculture's Agricultural Research Service. SWAT can be applied to large-scale river basins and in different time scales. It has been used extensively worldwide and shown to adequately reproduce the hydrological response of watersheds across a range of geographical regions and climates. SWAT is a physically based model able to estimate the impact of land uses on water, sediment, and agricultural chemicals on subcatchment and or land use unit scales over long periods of time, as well as responses of climate factors, for example, precipitation and evaporation, spatial variation of underlying surface factors, and human activities. By now, the SWAT model has been widely used in domestic and international basins for simulation of watershed hydrologic processes and hydrologic responses under the conditions of climate change and land use change, evaluation of human activities' impacts on ecological environments, and planning and management for regional water sources [31, 50, 51].

3.3.2. Simulation Methods. The precipitation input of the SWAT model is the daily precipitation at 9 stations. The model then calculates the areal precipitation for each subcatchment by using spatial interpolation method. Since only the daily precipitation data are available, the surface streamflow is estimated using the Soil Conservation Service (SCS) runoff curve number method. The Priestley-Taylor method was selected to calculate potential evapotranspiration (PET). According to the relationship between sensible heat flux and latent heat flux in wet surfaces and depending on the idea of evapotranspiration balance, Priestly and Taylor put forward the PET calculation formula under low-advective conditions. This method takes into consideration several meteorological elements such as solar radiation, soil heat flux, air temperature, and relative humidity. It has been proved to be applicable for calculating PET in humid areas by many researchers [52-54]. For river flood routing, the Muskingum method is adopted. The time scale of the streamflow simulation is monthly and the evaluation objective of parameter calibration is monthly streamflow efficiency coefficient.

3.3.3. SWAT Parameter Calibration. There are numerous parameters in the SWAT model, which can be classified into two types. Parameters of the first type can be directly determined by their physical meaning. The values of those attribute parameters such as soil physical properties and land use/land cover properties can be determined via the SWAT model database. Parameters of the second type are mainly related to discharge, including initial SCS runoff curve number for moisture condition $(\mathrm{CN})$, available water capacity of the soil layer (SOL_AWC), soil evaporation compensation factor (ESCO), groundwater reevaporation coefficient (GW_REVAP), and the baseflow recession constant (ALPHA$\mathrm{BF})$. This paper focuses on the watershed streamflow simulation and optimization of the second type of parameters. The parameter calibration process follows several principles: give upstream priority over downstream; first adjust the water balance and then the flow duration curve; and first adjust the surface flow and then the soil water, evaporation, and underground streamflow [31, 50,51]. In view of the complexity of the SWAT model, both automatic and manual calibration methods are used to optimize the second type of parameters.

3.4. Performance Criteria for Evaluating the Simulation. The Nash-Sutcliffe coefficient of efficiency (NSC), the coefficient of correlation (RC), and the relative error (ERR) (\%) are used to measure model performance. The expressions are given by

$$
\begin{aligned}
\mathrm{NSC} & =1-\frac{\sum_{i=1}^{n}\left(X_{\mathrm{obs}}^{i}-X_{\mathrm{sim}}^{i}\right)^{2}}{\sum_{i=1}^{n}\left(X_{\mathrm{obs}}^{i}-\overline{X_{\mathrm{obs}}}\right)^{2}}, \\
\mathrm{RC} & =\frac{\sum_{i=1}^{n}\left(X_{\mathrm{obs}}^{i}-\overline{X_{\mathrm{obs}}}\right)\left(X_{\mathrm{sim}}^{i}-\overline{X_{\mathrm{sim}}}\right)}{\sqrt{\sum_{i=1}^{n}\left(X_{\mathrm{obs}}^{i}-\overline{X_{\mathrm{obs}}}\right)^{2} \sum_{i=1}^{n}\left(X_{\mathrm{sim}}^{i}-\overline{X_{\mathrm{sim}}}\right)^{2}}}, \\
\mathrm{ERR} & =\frac{\sum_{i=1}^{n} X_{\mathrm{sim}}^{i}-\sum_{i=1}^{n} X_{\mathrm{obs}}^{i}}{\sum_{i=1}^{n} X_{\mathrm{obs}}^{i}} \times 100 \%,
\end{aligned}
$$

where $n$ is the number of time steps, $X_{\mathrm{obs}}^{i}$ is the observed data at time step $i, X_{\text {sim }}^{i}$ is the simulated data at time step $i, \overline{X_{\text {obs }}}$ is the mean value of the observed data, and $\overline{X_{\text {sim }}}$ is the mean value of the simulated data. The closer the values of NSC and RC are to 1 , the more successful the model calibration or validation is. Simulations are considered satisfactory when ERR is below $10 \%$ and excellent when ERR is less than 5\%.

\section{Results and Discussion}

4.1. Precipitation Downscaling Results. In this study, the first 30 years (1961-1990) is chosen for calibrating the models and the remaining data (1991-2009) are used for validation. The three models are tested for the period 1991-2009 for reproduction of various daily precipitation statistics. All downscaling methods are used with the same set of predictors for training. To assess the accuracy of the three downscaling models in producing rainfall inputs for hydrological model, a comparison of the predictors is selected including mean precipitation, 95th-percentile-of-rain-day amounts (P_95q, $\mathrm{mm}$ ), largest 5-day total rainfall (P_M5, mm), maximum length of wet spell (CWD, days), maximum length of dry spell (CDD, days), and percentage of days long-term exceeding 90th percentile (R90t, \%). The values of indictors are 
TABLE 2: Results of three statistical downscaling methods (calibration and validation).

\begin{tabular}{|c|c|c|c|c|c|c|c|c|c|}
\hline \multirow{2}{*}{$\begin{array}{l}\text { Statistical } \\
\text { indicators }\end{array}$} & \multirow{2}{*}{ Season } & \multicolumn{4}{|c|}{ Calibration } & \multicolumn{4}{|c|}{ Validation } \\
\hline & & Observation & SVM & BCC/RCG-WG & SDSM & Observation & SVM & BCC/RCG-WG & SDSM \\
\hline \multirow{5}{*}{ Mean/mm } & Spring & 2.30 & 2.17 & 2.04 & 2.12 & 1.76 & 1.61 & 1.54 & 1.83 \\
\hline & Summer & 4.33 & 4.41 & 4.19 & 4.37 & 4.03 & 4.06 & 3.75 & 4.19 \\
\hline & Autumn & 2.95 & 2.78 & 2.70 & 2.83 & 2.01 & 2.12 & 1.83 & 2.05 \\
\hline & Winter & 0.37 & 0.42 & 0.46 & 0.39 & 0.41 & 0.45 & 0.51 & 0.43 \\
\hline & Annual & 2.49 & 2.46 & 2.23 & 2.38 & 2.06 & 2.27 & 2.32 & 2.15 \\
\hline \multirow{5}{*}{ P_95q/mm } & Spring & 22.96 & 18.72 & 17.48 & 20.92 & 22.85 & 18.22 & 17.71 & 18.91 \\
\hline & Summer & 41.98 & 35.51 & 30.84 & 36.2 & 41.25 & 31.56 & 30.69 & 34.69 \\
\hline & Autumn & 26.98 & 25.41 & 20.56 & 23.96 & 24.88 & 22.28 & 20.3 & 21.14 \\
\hline & Winter & 7.58 & 5.74 & 4.97 & 6.13 & 7.71 & 5.47 & 4.88 & 5.53 \\
\hline & Annual & 28.51 & 23.99 & 20.93 & 25.65 & 28.85 & 23.06 & 21.13 & 23.83 \\
\hline \multirow{5}{*}{ P_M5/mm } & Spring & 114.16 & 122.68 & 111.79 & 126.21 & 98.83 & 93.37 & 90.92 & 99.56 \\
\hline & Summer & 233.99 & 190.81 & 165.14 & 207.7 & 213.71 & 181.54 & 180.13 & 181.07 \\
\hline & Autumn & 171.39 & 178.52 & 134.62 & 155.47 & 126.44 & 123.59 & 109.81 & 124.24 \\
\hline & Winter & 36.09 & 32.14 & 28.98 & 31.32 & 33.15 & 23.86 & 24.09 & 22.9 \\
\hline & Annual & 236.46 & 216.87 & 171.33 & 213.85 & 214.35 & 186.23 & 186.82 & 185.66 \\
\hline \multirow{5}{*}{$\mathrm{CDD} / \mathrm{d}$} & Spring & 23 & 20 & 18 & 19 & 20 & 21 & 15 & 24 \\
\hline & Summer & 19 & 17 & 13 & 18 & 23 & 24 & 11 & 20 \\
\hline & Autumn & 25 & 23 & 23 & 22 & 26 & 29 & 17 & 26 \\
\hline & Winter & 49 & 37 & 33 & 38 & 54 & 50 & 25 & 40 \\
\hline & Annual & 47 & 36 & 31 & 36 & 53 & 41 & 26 & 38 \\
\hline \multirow{5}{*}{$\mathrm{CWD} / \mathrm{d}$} & Spring & 10 & 11 & 15 & 11 & 9 & 8 & 15 & 8 \\
\hline & Summer & 12 & 11 & 17 & 13 & 11 & 9 & 18 & 10 \\
\hline & Autumn & 17 & 16 & 19 & 17 & 15 & 12 & 20 & 10 \\
\hline & Winter & 10 & 9 & 14 & 7 & 7 & 6 & 13 & 6 \\
\hline & Annual & 17 & 19 & 20 & 18 & 15 & 13 & 23 & 11 \\
\hline \multirow{5}{*}{ R90t/\% } & Spring & 39 & 36 & 44 & 37 & 36 & 40 & 44 & 38 \\
\hline & Summer & 63 & 59 & 65 & 60 & 64 & 61 & 66 & 62 \\
\hline & Autumn & 46 & 47 & 51 & 44 & 42 & 39 & 51 & 43 \\
\hline & Winter & 6 & 7 & 5 & 4 & 5 & 4 & 5 & 3 \\
\hline & Annual & 51 & 52 & 54 & 48 & 50 & 50 & 54 & 50 \\
\hline
\end{tabular}

shown in Table 2. The observed and predicted monthly precipitation time series during the validation period are shown in Figure 7(a), and the comparisons between observed monthly precipitations with monthly precipitations predicted by SDSM, SVM, and BCC/RCG-WG are shown in Figures $7(\mathrm{~b})-7(\mathrm{~d})$.

It can be seen that there is a small difference between the simulated and observed mean daily precipitation in all three methods. It is also evident that the simulation results of P_95q and CDD obtained by BCC/RCG-WG are close to those simulated by SVM and SDSM, while the other statistical indicators' simulation results by BCC/RCG-WG have a relatively large deviation. In addition, SDSM has a slight advantage compared with SVM in the simulation results of P_95q and R90t, showing that SDSM performs better at simulating precipitation extreme values. SVM is more effective to simulate CDD, and other indicators are similar to SDSM simulated results. The result of continuous dry days is better than continuous wet days, but both of the results are smaller compared with the observed variance. Therefore, the simulation accuracy for rain/no rain event needs to be further improved. SDSM has no significant advantage in individual indicator simulation but is slightly better than other two methods in overall stability through comparing simulation results of different seasons. In general, the SVM model can simulate rainfall distribution characteristics in the year better, while it is a little less than SDSM on the accuracy of extreme values in precipitation. This may be related to SDSM by precipitation of conditional probability to estimate rainfall.

The comparison results shown in Figure 7 also indicate that BCC/RCG-WG performed worse than SDSM and SVM, while SDSM performed a little better than SVM. The reason for the poor simulation by WG in recent years is associated with the parameter estimations using observed climate data before the year 2000. Since SDSM and SVM require the input of meteorological factors in corresponding years to 


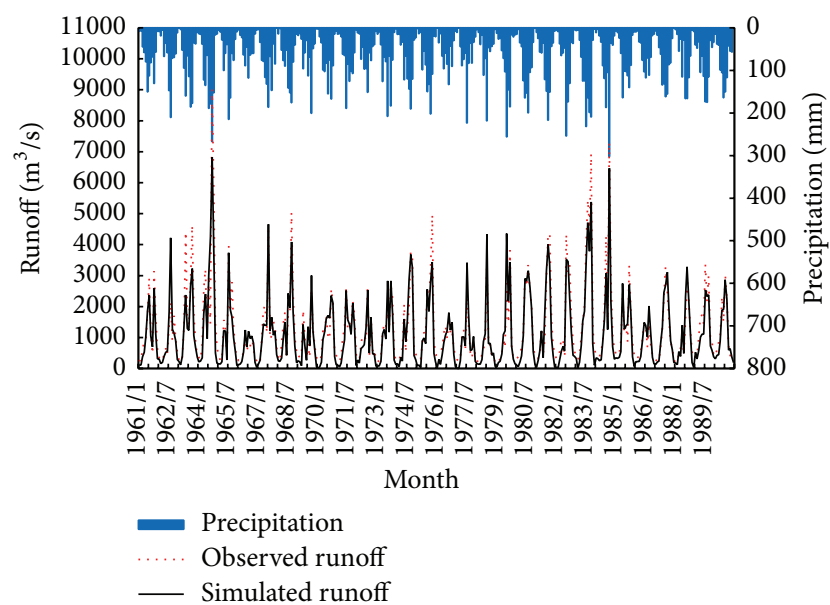

FIGURE 4: Comparison between simulated and observed monthly streamflow in the study area during calibration periods of 1961-1990.

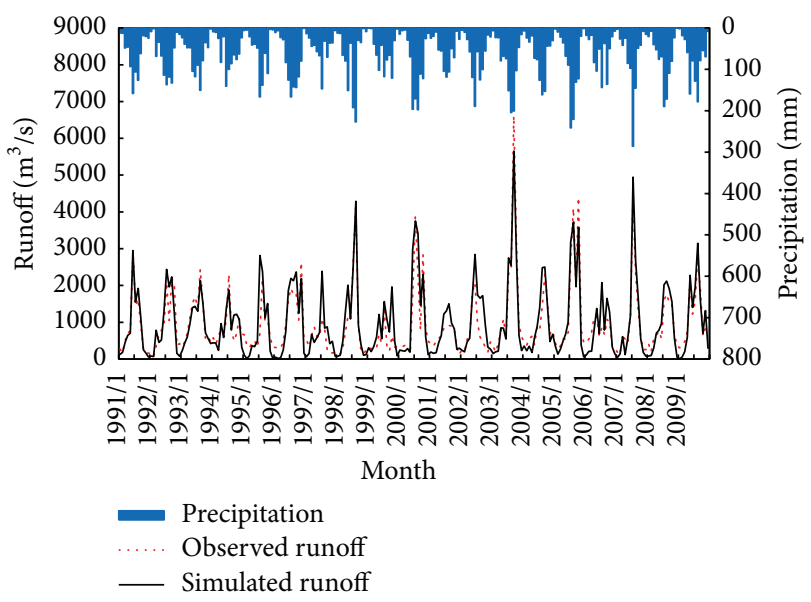

FIGURE 5: Comparison between simulated and observed monthly streamflow in the study area during validation periods of 1991-2009.

predict precipitation by using the established relationships between meteorological factors and precipitation, the results are relatively better than those obtained by BCC/RCG-WG. Comparing SVM and SDSM, the results by SDSM are a little better than SVM because all 10 factors in Table 1 were used in SVM, while the meteorological factors of each station are screened and the factors which correlated well with the precipitation are chosen in SDSM (see Table 6).

4.2. Simulation Analysis of SWAT Model. The historical records for DJK Reservoir over the period of 1961-2009 are split into two periods: 1961-1990 for calibration and 19912009 for validation. The SWAT model is first calibrated on the period 1961-1990 and then validated on the period 1991-2009. Model calibration and validation are conducted by comparing the SWAT simulated data with the observed discharge on a monthly basis. Figures 4 and 5 compare simulated monthly streamflow with observed streamflow values. Except for several years, most of the periods have a very good agreement between the simulated and observed
TABLE 3: Performance assessment of SWAT model during calibration and validation periods.

\begin{tabular}{lcccccc}
\hline & \multicolumn{3}{c}{ Calibration $(1960-1990)$} & \multicolumn{3}{c}{ Validation (1991-2009) } \\
& NSC & RC & ERR/\% & NSC & RC & ERR/\% \\
\hline All & 0.87 & 0.95 & -6.31 & 0.76 & 0.89 & -12.31 \\
Jan. & -10.48 & 0.27 & -76.87 & -5.60 & 0.27 & -83.79 \\
Feb. & -3.82 & 0.66 & -58.54 & -3.13 & 0.39 & -74.21 \\
Mar. & -0.15 & 0.80 & -28.33 & -3.79 & 0.36 & -50.24 \\
Apr. & 0.67 & 0.91 & 3.98 & -1.39 & 0.58 & -30.56 \\
May & 0.74 & 0.87 & 3.23 & 0.51 & 0.86 & -12.33 \\
Jun. & 0.73 & 0.91 & -5.58 & 0.73 & 0.93 & -11.73 \\
Jul. & 0.51 & 0.82 & 10.11 & 0.66 & 0.84 & 1.64 \\
Aug. & 0.65 & 0.88 & 10.78 & 0.82 & 0.91 & -1.77 \\
Sep. & 0.93 & 0.97 & -4.07 & 0.91 & 0.95 & -3.60 \\
Oct. & 0.92 & 0.97 & -11.20 & 0.88 & 0.94 & -6.15 \\
Nov. & -0.08 & 0.71 & -28.04 & 0.75 & 0.94 & -21.69 \\
Dec. & -3.98 & 0.58 & -67.21 & -2.34 & 0.72 & -76.35 \\
\hline
\end{tabular}

streamflow. The different performance measures, including the Nash-Sutcliffe coefficient of efficiency (NSC), the coefficient of correlation (RC), and the relative error (ERR) between the model outputs and the observed data, are also summarized in Table 3. In the model calibration period, the relative error for monthly average streamflow is $-6.31 \%$, and RC and NSC are 0.95 and 0.85 , respectively. All the three are within the range of satisfactory accuracy. The model validation result shows that the model gives satisfactory and comparable performance on the streamflow simulation. Model performance over the validation period is acceptable, with values of $-12.31 \%$ for ERR, 0.89 for RC, and 0.76 for NSC. Because the monthly data include the seasonal cycle, the correlation is very high. Thus to objectively evaluate the predictability, the performance of each month is shown in Table 3. Considering individual months, the simulation results show good performance from May to October, although the accuracy was quite low from December to February. In other words, the SWAT model can operate well in the wet season but it is less accurate in the dry season, like many other hydrological models. In general, the results indicate that it is feasible to apply the SWAT distributed hydrological model to streamflow simulations.

\subsection{Simulation Results Analysis of Ensemble Downscaling Method Based on BMA}

4.3.1. Precipitation Simulation. Ensemble downscaling method based on BMA combined with SVM, BCC/RCGWG, and SDSM model is set up and a weighted average of precipitation sequences from 1991 to 2009 is simulated. And the NSC and RC of the nine stations are calculated by ensemble downscaling method based on BMA and compared with single downscaling model (SVM, BCC/RCGWG, and SDSM) and the simple averaged (SA) ensemble method. The compared values are shown in Table 4 . Figure 6 presents the effect of the BMA method through comparing the mean value of evaluation indictors of the nine 
TABLE 4: Different methods precipitation simulation results comparison.

\begin{tabular}{lcccccccccc}
\hline \multirow{2}{*}{ Stations } & \multicolumn{2}{c}{ SVM } & \multicolumn{2}{c}{ BCC/RCG-WG } & \multicolumn{2}{c}{ SDSM } & \multicolumn{2}{c}{ BMA } & SA \\
& NSC & RC & NSC & RC & NSC & RC & NSC & RC & NSC & RC \\
\hline Hanzhong & 0.32 & 0.58 & -1.1 & 0.07 & 0.31 & 0.57 & 0.29 & 0.62 & 0.20 & 0.46 \\
Foping & 0.31 & 0.56 & -0.8 & 0.11 & 0.29 & 0.54 & 0.24 & 0.59 & 0.22 & 0.47 \\
Shangxian & 0.14 & 0.39 & -0.75 & 0.06 & 0.26 & 0.51 & 0.20 & 0.55 & 0.15 & 0.40 \\
Xixia & 0.19 & 0.44 & -0.98 & 0.04 & 0.22 & 0.49 & 0.19 & 0.52 & 0.09 & 0.32 \\
Shiquan & 0.28 & 0.54 & -0.78 & 0.04 & 0.25 & 0.51 & 0.22 & 0.55 & 0.16 & 0.40 \\
Ankang & 0.21 & 0.48 & -0.74 & 0.07 & 0.23 & 0.48 & 0.19 & 0.52 & 0.16 & 0.40 \\
Yunxian & 0.23 & 0.52 & -1.21 & 0.02 & 0.31 & 0.57 & 0.27 & 0.62 & 0.16 & 0.41 \\
Fangxian & 0.25 & 0.51 & -0.92 & 0.04 & 0.24 & 0.49 & 0.25 & 0.57 & 0.14 & 0.38 \\
Laohekou & 0.23 & 0.48 & -0.87 & 0.02 & 0.27 & 0.54 & 0.26 & 0.59 & 0.13 & 0.37 \\
Mean values & 0.24 & 0.50 & -0.91 & 0.05 & 0.26 & 0.52 & 0.23 & 0.57 & 0.16 & 0.40 \\
\hline
\end{tabular}

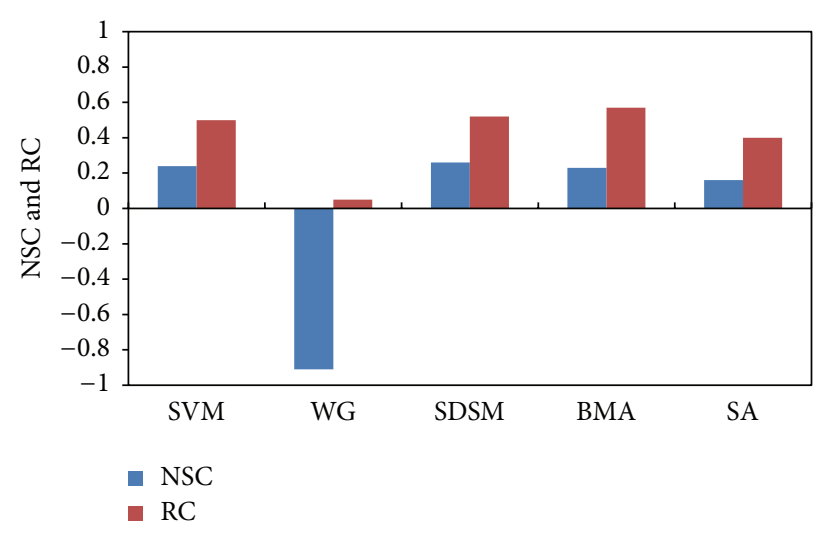

FIGURE 6: BMA method compared with single simulated rainfall downscaling method.

stations. It can be seen from Table 4 that the efficiency coefficients of precipitation sequence are negative, and correlation coefficients are all below 0.11 when simulated using BCC/RCG-WG. It demonstrates that the simulated precipitation process by BCC/RCG-WG has a big difference compared with the observed data which corresponding to the efficiency coefficient of BMA approach to improve the effect is not obvious. The correlation coefficients calculated by the BMA method are greater than the three single downscaling models and the SA ensemble method, and the comparison result of correlation coefficients indicates that the BMA method could improve the correlation between simulated and measured values. Because the same weight is applied to each individual method in the SA ensemble method, the simulation effect of SA is better than WG but worse than SVM and SDSM. However, the simulation forced by the BMA ensemble outperformed not only the simulations forced by individual reanalysis datasets, but also the equal-weight ensemble simulated precipitation. These results suggest that the BMA ensemble method is an effective method for improving model performance in climate downscaling.

4.3.2. Runoff Simulation. In order to fully analyze the effect of rainfall-runoff simulation using the BMA method, the daily precipitation sequences obtained by SVM, BCC/RCG-WG, SDSM, SA, and ensemble downscaling method based on BMA are put into the SWAT model which is calibrated well in the above content. The simulated runoff results from 1991 to 2009 are compared with the measured data, and the evaluation indictors are listed in Table 5 and the runoff process is shown in Figure 8 . The runoff coefficient is only about 0.2 when using the input daily precipitation downscaled by the BCC/RCG-WG model. The value is significantly lower compared with the runoff coefficients calculated by input of the precipitation downscaled using SVM and SDSM. From the specific values of relative error, BCC/RCG-WG model shows well at simulating the total amount of precipitation while it is poor at grasping the process of precipitation.

The simulated runoff processes are similar by input of the precipitation using SVM and SDSM method and the response to the runoff of these two models is almost the same, but the relative error of the indicators is significantly greater than the measured ones. This indicates that there are great uncertainties when simulating the precipitation through downscaling method. The NSC of simulated runoff calculated by input precipitation downscaled using SVM is bigger than that using the SDSM. But from the ERR which reflects the total error, we can see that SVM performs a little better. This runoff simulation result does not agree with the downscaling precipitation results. In the downscaling precipitation results, SDSM can describe the precipitation more reasonably. From the point that precipitation is the main factor affecting the runoff, the idea that evaluation indictors can describe precipitation well may not accurately describe the runoff and the correlation characteristics between rainfall and runoff. Similarly, the runoff simulation by SA ensemble method is better than WG but worse than SVM and SDSM. It can be seen that the simulated runoff accuracy is improved when inputting the weighted average precipitation by BMA compared with the single downscaling method. Also, the efficiency coefficient and correlation coefficient are slightly increased, and the relative error obviously decreases.

In general, due to the uncertainty and randomness of precipitation simulation, statistical downscaling method is focused on the statistical distribution characteristics rather 


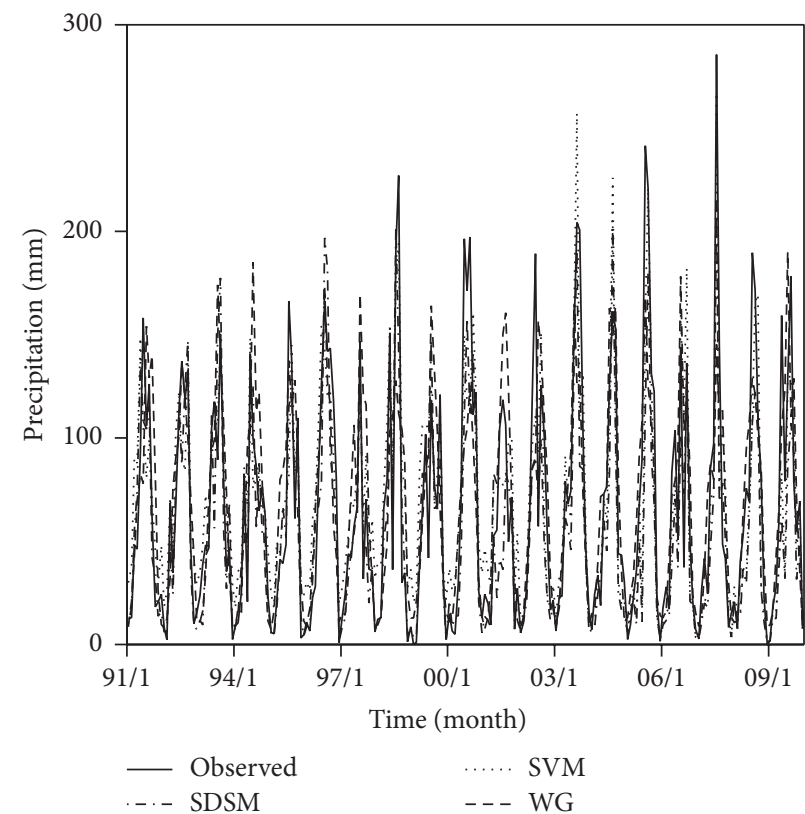

(a)

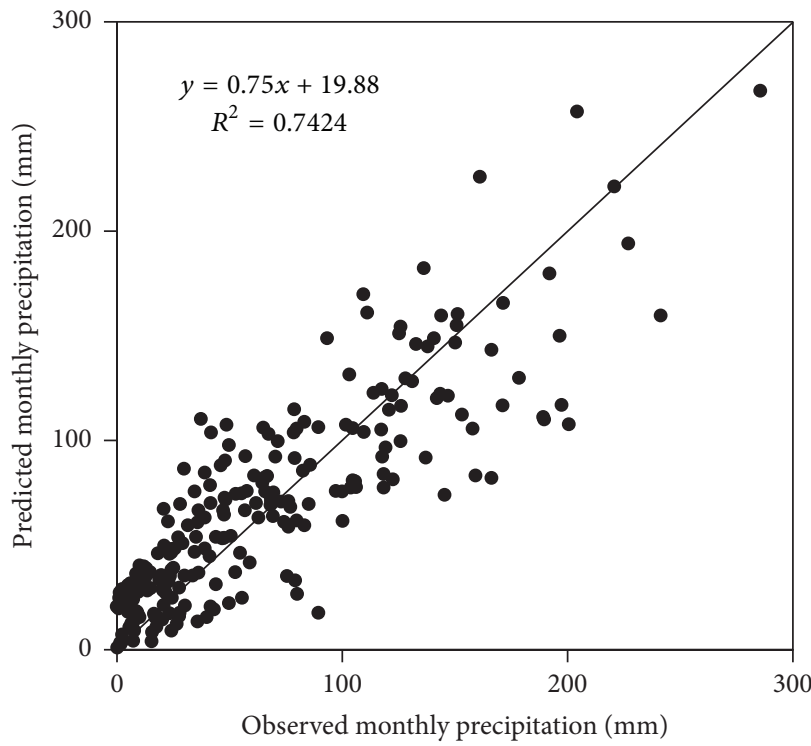

(c)

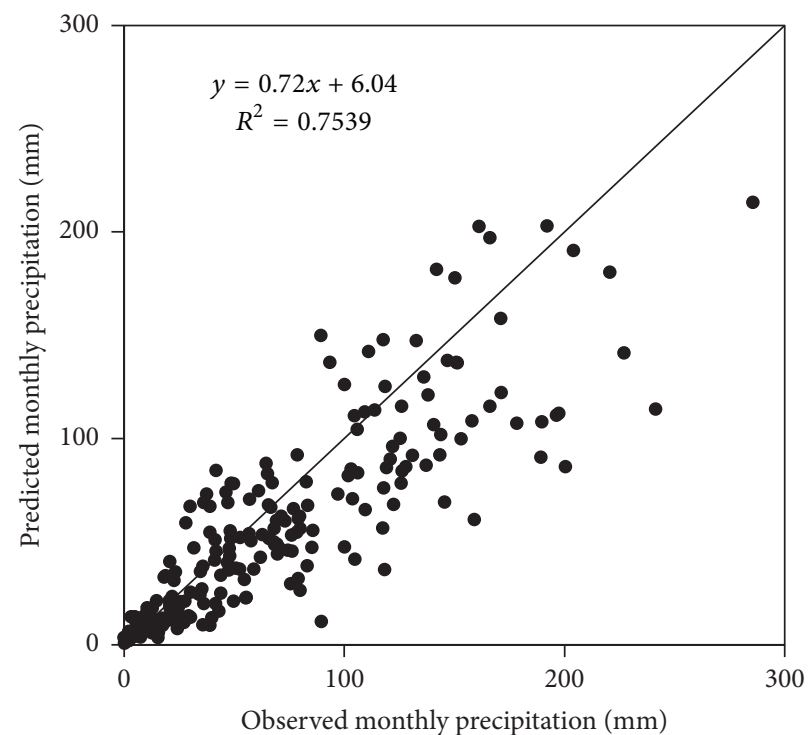

(b)

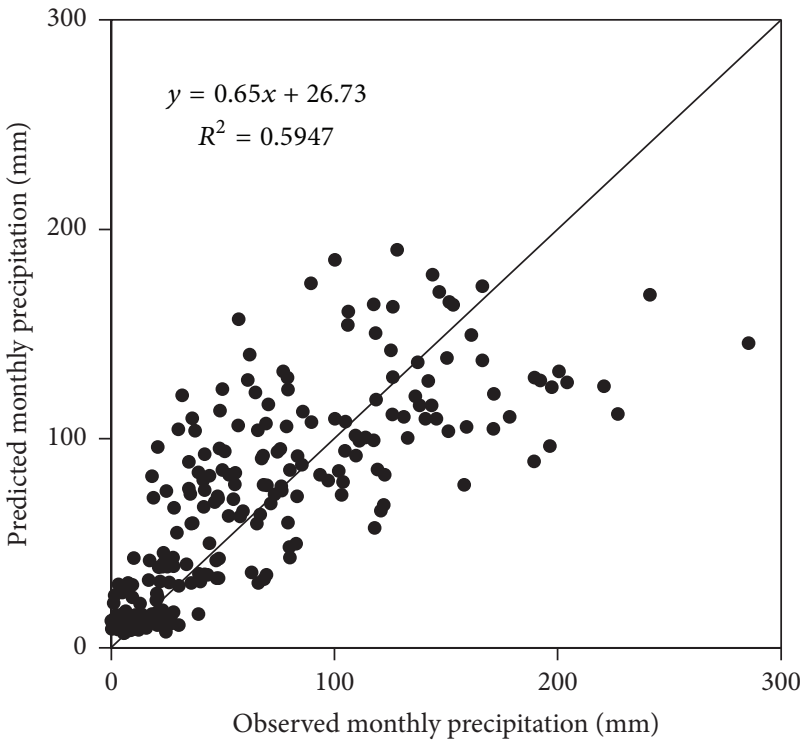

(d)

FIGURE 7: (a) Monthly precipitation time series of observed data and data predicted by three methods and the relationship of observed monthly precipitation with monthly precipitations predicted by (b) SDSM, (c) SVM, and (d) BCC/RCG-WG.

than errors of the precipitation process. Therefore, the statistical downscaling methods should be improved at comprehensive analysis of the precipitation simulation and collected methods together to get better effects.

\section{Conclusions}

This paper first assesses the three downscaling models which are SVM, BCC/RCG-WG, and SDSM by comparing the predictands against observed historical data and then evaluates the runoff modelled by the SWAT rainfall-runoff model using the downscaled daily rainfall against observed historical runoff characteristics and further proposed ensemble downscaling method based on BMA combined with the above three statistical downscaling models; at the same time the performance of each model is measured by the chosen indexes. In particular, the downscaled precipitation from all these methods is put into the SWAT model for detailed comparison and analysis. The specific conclusions are as follows.

(1) In terms of mean precipitation, the downscaled results are close to the observed data, while for the other predictors each downscaling model has different performance. For the ability to estimate precipitation events and simulate the distribution of rainfall during the year, SVM performs well. SDSM has no significant advantage in the assessment of 
TABLE 5: The BMA method precipitation runoff result of input analog.

\begin{tabular}{lccc}
\hline Input precipitation & NSC & RC & ERR/\% \\
\hline Observed & 0.76 & 0.89 & -12.31 \\
SVM & 0.52 & 0.77 & 20.1 \\
BCC/RCG-WG & 0.19 & 0.55 & 5.52 \\
SDSM & 0.50 & 0.76 & 23.46 \\
SA & 0.38 & 0.68 & 18.5 \\
BMA & 0.56 & 0.79 & 13.74 \\
\hline
\end{tabular}

TABLE 6: The forecast factors of each station for SDSM.

\begin{tabular}{lc}
\hline Station & Forecast factors \\
\hline Hanzhong & Temp, p500, r500, r850, and p5_v \\
Foping & Temp, p500, r500, r850, and p5_v \\
Shangxian & Temp, p500, r500, r850, and p5_v \\
Xixia & Temp, p500, r500, r850, p8_u, and p5_v \\
Shiquan & Temp, p500, r500, r850, and p5_v \\
Ankang & Temp, p500, r500, r850, and p5_v \\
Yunxian & Temp, p500, r500, r850, and p5_v \\
Fangxian & Temp, p500, r500, r850, p8_u, and p5_v \\
Laohekou & Temp, p500, r500, r850, and p5_v \\
\hline
\end{tabular}

individual indicators but slightly higher accuracy can be obtained on the indicators that reflect precipitation extremes. The ensemble downscaling method based on BMA is proposed by combining the three statistical downscaling models and the results show it can improve the correlation between simulated and measured values.

(2) The SWAT rainfall-runoff hydrological model is used to simulate monthly runoff. With calibration on the period of 1961-1990 and validation on the period of 1991-2009, the model gives satisfactory and comparable performance on the streamflow simulation in the study area.

(3) Daily downscaled precipitation simulated using the three models and the ensemble downscaling method based on BMA is obtained and separately put into the SWAT model. By comparing the simulated runoff derived from precipitation of the ensemble downscaling method based on BMA and the three individual models, it can be seen that the BMA method may improve the runoff simulation effect to a certain extent and reduce the simulation uncertainty of both precipitation and runoff.

Based on the study, it is found that BMA is a particularly useful method. It can assess the relative performances of all models by assigning weights to each model when there are two or more competing models available for the same issue and then produce more accurate mean prediction by weighted averaging of all predictions from those models. In the next step, more evaluation indicators can be considered, and more downscaling methods and hydrological models can be applied to analyze their feasibility in other basins.

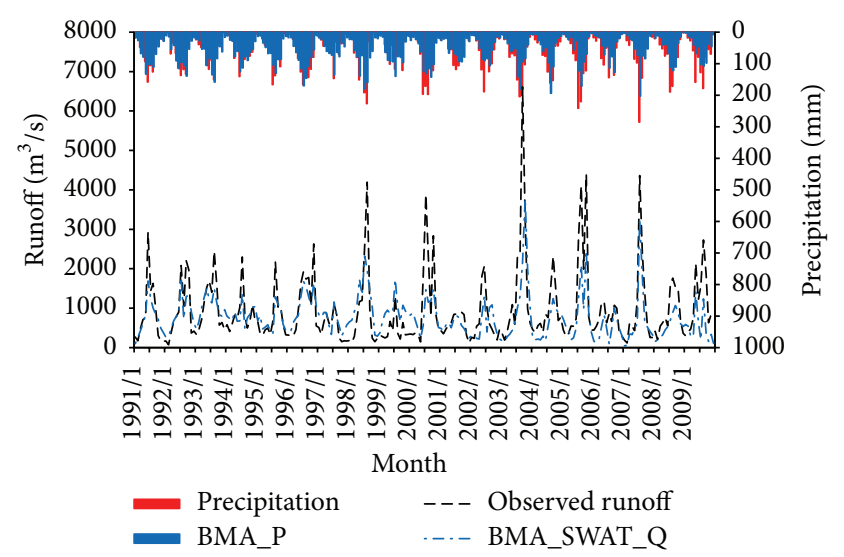

FIGURE 8: Simulated monthly streamflow by SWAT model through inputting the precipitation obtained using BMA method. The red and blue solid curves are precipitation with values shown on the right $y$-axis, while the black and blue-dashed curves are runoff with values shown on the left $y$-axis. The scales have been adjusted to avoid overlapping of the curves.

\section{Conflict of Interests}

The authors declare that there is no conflict of interests regarding the publication of this paper.

\section{Acknowledgments}

This study was supported by the State Key Program of National Natural Science of China (no. 51339004), the National Natural Science Foundation of China (nos. 51379149, 51209162, and 51279143), the Major Science and Technology Program for Water Pollution Control and Treatment of China (2014ZX07104-005). The authors appreciate the constructive comments of the excellent reviews of the Coordinating Editor and anonymous reviewers.

\section{References}

[1] C.-Y. Xu, "Climate change and hydrologic models: a review of existing gaps and recent research developments," Water Resources Management, vol. 13, no. 5, pp. 369-382, 1999.

[2] J. Sun and H. Chen, "A statistical downscaling scheme to improve global precipitation forecasting," Meteorology and Atmospheric Physics, vol. 117, no. 3, pp. 87-102, 2012.

[3] S. L. Grotch and M. C. MacCracken, "The use of general circulation models to predict regional climatic change," Journal of Climate, vol. 4, no. 3, pp. 286-303, 1991.

[4] R. L. Wilby and T. M. L. Wigley, "Downscaling general circulation model output: a review of methods and limitations," Progress in Physical Geography, vol. 21, no. 4, pp. 530-548, 1997.

[5] R. L. Wilby, L. E. Hay, and G. H. Leavesley, "A comparison of downscaled and raw GCM output: implications for climate change scenarios in the San Juan River Basin, Colorado," Journal of Hydrology, vol. 225, no. 1-2, pp. 67-91, 1999.

[6] I. Hanssen-Bauer, C. Achberger, R. E. Benestad, D. Chen, and E. J. Førland, "Statistical downscaling of climate scenarios over Scandinavia," Climate Research, vol. 29, no. 3, pp. 255-268, 2005. 
[7] H. J. Fowler, S. Blenkinsop, and C. Tebaldi, "Linking climate change modelling to impacts studies: recent advances in downscaling techniques for hydrological modelling," International Journal of Climatology, vol. 27, no. 12, pp. 1547-1578, 2007.

[8] E. Zorita and H. von Storch, "The analog method as a simple statistical downscaling technique: comparison with more complicated methods," Journal of Climate, vol. 12, no. 8, pp. 24742489, 1999.

[9] Y. B. Dibike and P. Coulibaly, "Hydrologic impact of climate change in the Saguenay watershed: comparison of downscaling methods and hydrologic models," Journal of Hydrology, vol. 307, no. 1-4, pp. 145-163, 2005.

[10] M. S. Khan, P. Coulibaly, and Y. Dibike, "Uncertainty analysis of statistical downscaling methods," Journal of Hydrology, vol. 319, no. 1-4, pp. 357-382, 2006.

[11] D. J. Reid, "Combining three estimates of gross domestic product," Economica, vol. 35, no. 140, pp. 431-444, 1968.

[12] J. M. Bates and C.W. J. Granger, "The combination of forecasts," Operational Research Quarterly, vol. 20, no. 4, pp. 451-468, 1969.

[13] J. P. Dickinson, "Some statistical results in the combination of forecasts," Operational Research Quarterly, vol. 24, no. 2, pp. 253-260, 1973.

[14] A. Y. Shamseldin, K. M. O’Connor, and G. C. Liang, "Methods for combining the outputs of different rainfall-runoff models," Journal of Hydrology, vol. 197, no. 1-4, pp. 203-229, 1997.

[15] K. P. Georgakakos, D.-J. Seo, H. Gupta, J. Schaake, and M. B. Butts, "Towards the characterization of streamflow simulation uncertainty through multimodel ensembles," Journal of Hydrology, vol. 298, no. 1-4, pp. 222-241, 2004.

[16] N. K. Ajami, Q. Duan, H. Moradkhani, and S. Sorooshian, "Recursive Bayesian model combination for streamflow forecasting," in Proceedings of the American Meteorological Society Meeting, San Diego, Calif, USA, January 2005.

[17] N. K. Ajami, Q. Duan, X. Gao, and S. Sorooshian, "Multimodel combination techniques for analysis of hydrological simulations: application to distributed model intercomparison project results," Journal of Hydrometeorology, vol. 7, no. 4, pp. 755-768, 2006.

[18] N. K. Ajami, Q. Duan, and S. Sorooshian, "An integrated hydrologic Bayesian multimodel combination framework: confronting input, parameter, and model structural uncertainty in hydrologic prediction," Water Resources Research, vol. 43, no. 1, Article ID W01403, 2007.

[19] D. Madigan and A. E. Raftery, "Model selection and accounting for model uncertainty in graphical models using Occam's window," Journal of the American Statistical Association, vol. 89, no. 428, pp. 1535-1546, 1994.

[20] A. E. Raftery, "Bayesian model selection in social research," Sociological Methodology, vol. 25, pp. 111-163, 1995.

[21] D. Draper, "Assessment and propagation of model uncertainty," Journal of the Royal Statistical Society B. Methodological, vol. 57, no. 1, pp. 45-97, 1995.

[22] C. Fernández, E. Ley, and M. F. J. Steel, "Benchmark priors for Bayesian model averaging," Journal of Econometrics, vol. 100, no. 2, pp. 381-427, 2001.

[23] K. Y. Yeung, R. E. Bumgarner, and A. E. Raftery, "Bayesian model averaging: development of an improved multi-class, gene selection and classification tool for microarray data," Bioinformatics, vol. 21, no. 10, pp. 2394-2402, 2005.
[24] B. A. Wintle, M. A. McCarthy, C. T. Volinsky, and R. P. Kavanagh, "The use of bayesian model averaging to better represent uncertainty in ecological models," Conservation Biology, vol. 17, no. 6, pp. 1579-1590, 2003.

[25] K. H. Morales, J. G. Ibrahim, C.-J. Chen, and L. M. Ryan, "Bayesian model averaging with applications to benchmark dose estimation for arsenic in drinking water," Journal of the American Statistical Association, vol. 101, no. 473, pp. 9-17, 2006.

[26] G. Koop and L. Tole, "Measuring the health effects of air pollution: to what extent can we really say that people are dying from bad air?" Journal of Environmental Economics and Management, vol. 47, no. 1, pp. 30-54, 2004.

[27] A. E. Raftery, F. Balabdaoui, T. Gneiting, and M. Polakowski, "Using Bayesian model averaging to calibrate forecast ensembles," Tech. Rep. 440, Department of Statistics, University of Washington, 2003.

[28] V. Viallefont, A. E. Raftery, and S. Richardson, "Variable selection and Bayesian model averaging in case-control studies," Statistics in Medicine, vol. 20, no. 21, pp. 3215-3230, 2001.

[29] J. A. Hoeting, D. Madigan, A. E. Raftery, and C. T. Volinsky, "Bayesian model averaging: a tutorial," Statistical Science, vol. 14 , no. 4, pp. 382-417, 1999.

[30] "Bayesian model averaging and model search strategies," in Bayesian Statistics, M. A. Clyde, J. M. Bernardo, A. P. Dawid, J. O. Berger, and A. F. M. Smith, Eds., vol. 6, pp. 157-185, Oxford University Press, Oxford, UK, 1999.

[31] A. E. Raftery and Y. Zheng, "Discussion: performance of bayesian model averaging," Journal of the American Statistical Association, vol. 98, no. 464, pp. 931-938, 2003.

[32] S. P. Neuman, "Maximum likelihood Bayesian averaging of uncertain model predictions," Stochastic Environmental Research and Risk Assessment, vol. 17, no. 5, pp. 291-305, 2003.

[33] Q. Duan, N. K. Ajami, X. Gao, and S. Sorooshian, "Multimodel ensemble hydrologic prediction using Bayesian model averaging," Advances in Water Resources, vol. 30, no. 5, pp. 13711386, 2007.

[34] L. Zhang, X. Chen, X. Zhang, and X. Song, "Comparative study on streamflow simulation in small and middle watersheds via VIC model and SWAT model," Yangtze River Resources and Environment, vol. 18, no. 8, pp. 745-752, 2009.

[35] H. Yang, B. Wang, and B. Wang, "Reducing biases in regional climate downscaling by applying Bayesian model averaging on large-scale forcing," Climate Dynamics, vol. 39, no. 9-10, pp. 2523-2532, 2012.

[36] S. Tripathi, V. V. Srinivas, and R. S. Nanjundiah, "Downscaling of precipitation for climate change scenarios: a support vector machine approach," Journal of Hydrology, vol. 330, no. 3-4, pp. 621-640, 2006.

[37] X. Y. Yu and S.-Y. Liong, "Forecasting of hydrologic time series with ridge regression in feature space," Journal of Hydrology, vol. 332, no. 3-4, pp. 290-302, 2007.

[38] L. Yaoming, Z. Qiang, and C. Deliang, "Stochastic modeling of daily precipitation in China," Journal of Geographical Sciences, vol. 14, no. 4, pp. 417-426, 2004.

[39] Y. Liao, "Change of parameters of BCC/RCG-WG for daily non-precipitation variables in China: 1951-1978 and 1979-2007," Journal of Geographical Sciences, vol. 23, no. 4, pp. 579-594, 2013.

[40] R. L. Wilby, C. W. Dawson, and E. M. Barrow, "SDSM-a decision support tool for the assessment of regional climate change impacts," Environmental Modelling and Software, vol. 17, no. 2, pp. 147-159, 2002. 
[41] H. Chen, J. Guo, W. Xiong, S. Guo, and C. Xu, "Downscaling GCMs using the Smooth Support Vector Machine method to predict daily precipitation in the Hanjiang Basin," Advances in Atmospheric Sciences, vol. 27, no. 2, pp. 274-284, 2010.

[42] V. N. Vapnik, The Nature of Statistical Learning Theory, Springer-Verlag, New York, NY, USA, 1995.

[43] V. N. Vapnik, Statistical Learning Theory, Wiley, New York, NY, USA, 1998.

[44] S. Ghosh and P. P. Mujumdar, "Statistical downscaling of GCM simulations to streamflow using relevance vector machine," Advances in Water Resources, vol. 31, no. 1, pp. 132-146, 2008.

[45] A. Anandhi, V. V. Srinivas, R. S. Nanjundiah, and D. N. Kumar, "Downscaling precipitation to river basin in India for IPCC SRES scenarios using support vector machine," International Journal of Climatology, vol. 28, no. 3, pp. 401-420, 2008.

[46] J. A. K. Suykens and J. Vandewalle, "Least squares support vector machine classifiers," Neural Processing Letters, vol. 9, no. 3, pp. 293-300, 1999.

[47] C. Harpham and R. L. Wilby, "Multi-site downscaling of heavy daily precipitation occurrence and amounts," Journal of Hydrology, vol. 312, no. 1-4, pp. 235-255, 2005.

[48] R. L. Wilby and M. D. Dettinger, "Streamflow changes in the Sierra Nevada, California, simulated using a statistically downscaled general circulation model scenario of climate change," in Linking Climate Change to Land Surface Change, vol. 6 of Advances in Global Change Research, pp. 99-121, Springer, Dordrecht, The Netherlands, 2000.

[49] F. Wetterhall, S. Halldin, and C. Y. Xu, "Seasonality properties of four statistical-downscaling methods in central Sweden," Theoretical and Applied Climatology, vol. 87, no. 1, pp. 123-137, 2007.

[50] J. Schuol, K. C. Abbaspour, R. Srinivasan, and H. Yang, "Estimation of freshwater availability in the West African sub-continent using the SWAT hydrologic model," Journal of Hydrology, vol. 352, no. 1-2, pp. 30-49, 2008.

[51] D. L. Ficklin, Y. Luo, E. Luedeling, and M. Zhang, "Climate change sensitivity assessment of a highly agricultural watershed using SWAT," Journal of Hydrology, vol. 374, no. 1-2, pp. 16-29, 2009.

[52] S. Peng and J. Xu, "Comparative study on reference crop's evapotranspiration calculation methods," Journal of Irrigation and Drainage, vol. 23, no. 6, pp. 5-9, 2004 (Chinese).

[53] C.-Y. Xu, L. Gong, T. Jiang, D. Chen, and V. P. Singh, "Analysis of spatial distribution and temporal trend of reference evapotranspiration and pan evaporation in Changjiang (Yangtze River) catchment," Journal of Hydrology, vol. 327, no. 1-2, pp. 81-93, 2006.

[54] G. Pang, S. Peng, J. Ding, J. Xu, J. Cui, and Z. Wei, “Experimental study on the water demand laws for lawns in southern climate regions," Journal of Hohai University (Natural Science), vol. 37, no. 2, pp. 143-146, 2009 (Chinese). 

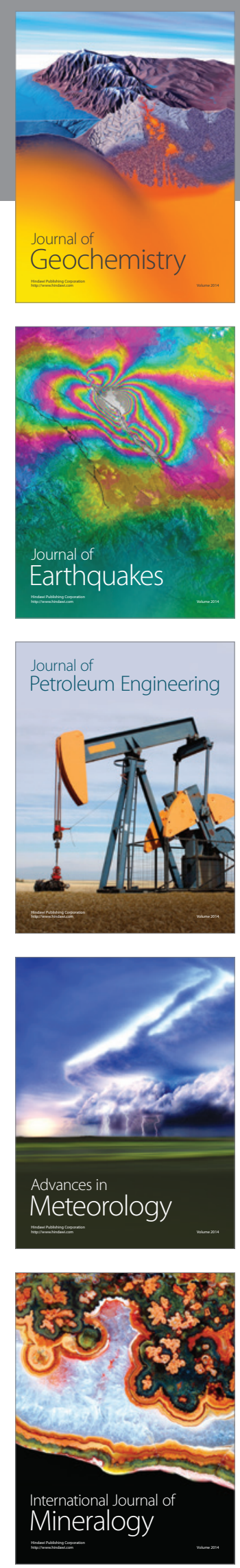
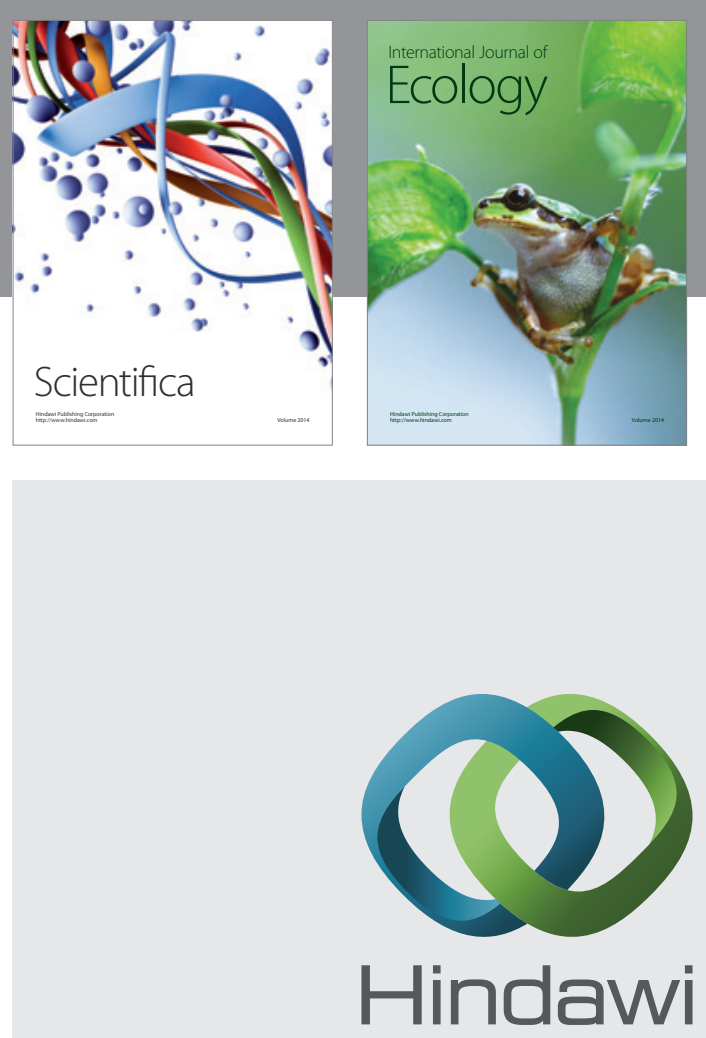

Submit your manuscripts at

http://www.hindawi.com
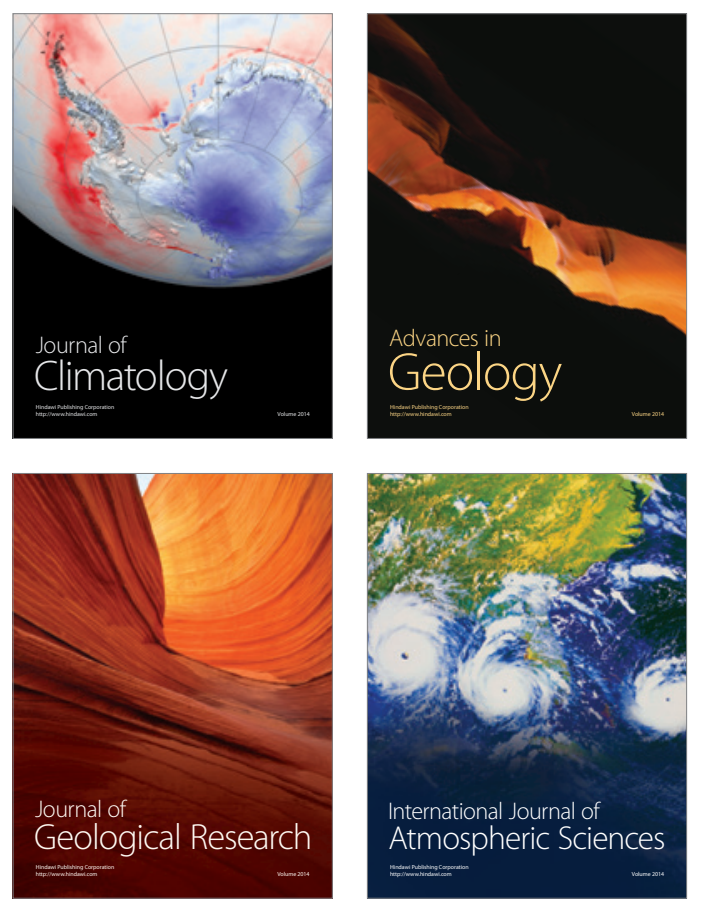

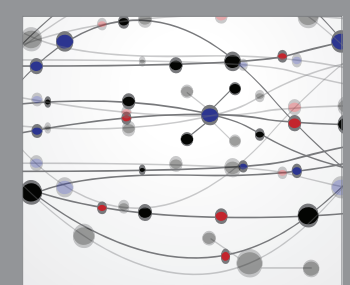

The Scientific

\section{World Journal}
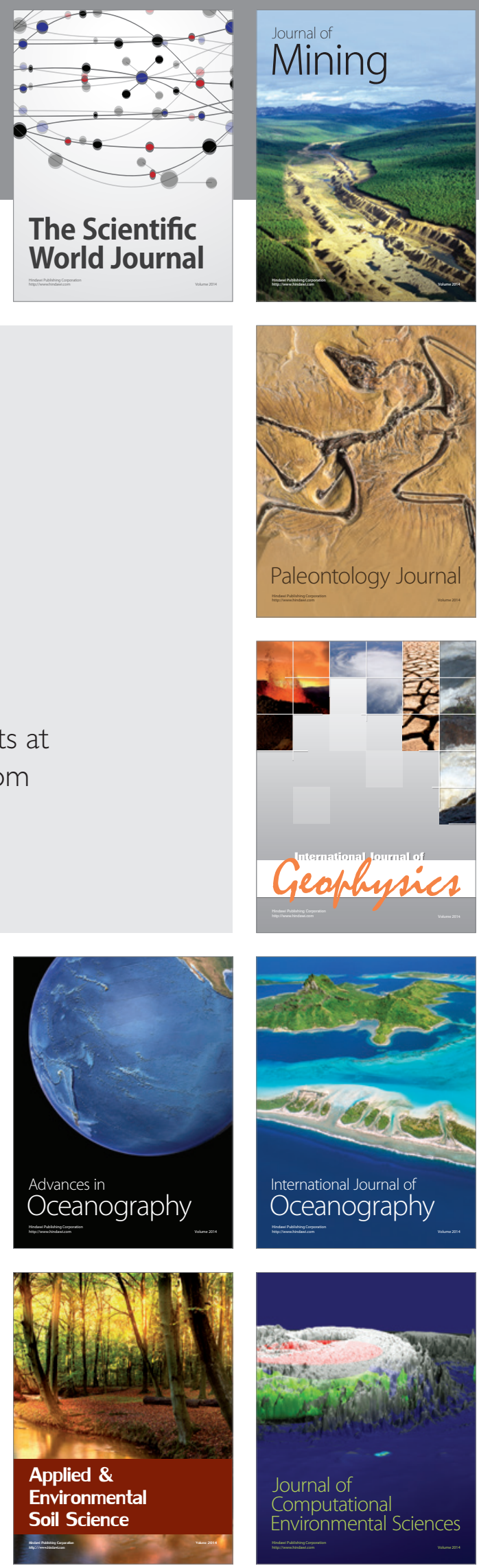